\title{
Comparison of Depth of Cure, Hardness and Heat Generation of LED and High Intensity QTH Light Sources
}

Sayed Mostafa Mousavinasaba

Ian Meyers ${ }^{b}$

\section{ABSTRACT}

Objectives: To compare curing performance of a second generation LED curing light with a high power tungsten quartz halogen (QTH).

Methods: A hybrid composite resin (Filtek Z 250, 3M, USA) was used as test material and cured using a second generation LED light (Translux Power Blue ${ }^{T M}$, Heraus Kulzer ,Germany) or a very high power QTH light unit (EMS, Switzerland). A two split aluminum mold was used to prepare ten samples with LED light source cured for forty seconds and ten samples prepared using high power QTH light unit, cured for four or six seconds recommended exposure time. Hardness, depth of cure (DOC) and thermal rise during exposure time by these light sources were measured. The data submitted to analysis of variance (ANOVA), Tukey's and student's t tests at $5 \%$ significance level.

Results: Significant differences were found in hardness, DOC of samples cured by above mentioned light sources and also in thermal rises during exposure time. The curing performance of the tested QTH was not as well as the LED light. TPB light source produced the maximum hardness $(81.25,73.29,65.49,55.83$ and 24.53 for $0 \mathrm{~mm}, 1 \mathrm{~mm}, 2 \mathrm{~mm}, 3 \mathrm{~mm}$ and $4 \mathrm{~mm}$ intervals) and DOC (2.64 $\mathrm{mm}$ ) values with forty seconds irradiation time and the high power (QTH) the least hardness (73.27, 61.51 and 31.59 for $0 \mathrm{~mm}, 1 \mathrm{~mm}$ and $2 \mathrm{~mm}$, respectively) and DOC ( $2 \mathrm{~mm}$ ) values with four seconds irradiation time. Thermal rises during $4 \mathrm{~s}$ and $6 \mathrm{~s}$ curing time using high power QTH and tested LED were $1.88^{\circ} \mathrm{C}, 3^{\circ} \mathrm{C}$ and $1.87^{\circ} \mathrm{C}$, respectively.

Conclusions: The used high power LED light produced greater hardness and depth of cure during forty seconds exposure time compared to high power QTH light with four or six seconds curing time. Thermal rise during 6 s curing time with QTH was greater compared to thermal changes occurred during $40 \mathrm{~s}$ curing time with tested LED light source. There was no difference seen in thermal changes caused by LED light with $40 \mathrm{~s}$ and QTH light with $4 \mathrm{~s}$ exposure time. (Eur J Dent 2011;5:299304)

Key words: Hardness; Depth of cure; Resin composite; Heat generation.

Associate Professor, Department of Restorative Dentistry, Torabinejad Research Dental Center, School of Dentistry, Isfahan University of Medical Sciences and Health Services, Isfahan, Iran.

b Professor, Colgate Chair of General Practice Dentistry, The University of Queensland, Brisbane, Australia.
Corresponding author: Sayed Mostafa Mousavinasab Department of Restorative Dentistry, Torabinejad Research Dental Centre, School of Dentistry, Isfahan University of Medical Sciences and Health Services, Isfahan, Iran.

Phone: +98 3117922849 Fax : +98 3116687080

E-mail: S_mousavinasabadnt.mui.ac.ir 


\section{INTRODUCTION}

Light emitting diode (LED) light curing units are becoming increasingly popular in dental practice. Most of the first-generation LED light units were unable to cure composite resin in the manner of quartz-tungsten-halogen (QTH) light sources. ${ }^{1-5}$ Since the spectral output of the LEDs is concentrated in the blue wavelength range, high power LED curing lights are capable of polymerizing some resins as well as, or better than, some QTH lights. ${ }^{6-8}$ LED curing units are characterized by a relatively narrow emission spectrum and lower heat generation than QTH curing units. .,9-14 $^{-14}$

There have been reports that exposure causes less temperature rise with a conventional curing light than with an LED curing light and that higher pulp chamber temperature changes are induced by high output curing units than by conventional curing units. ${ }^{15-16}$ Likewise, previous findings that had indicated less temperature rise with LED units than with QTH units have been debated in another study. ${ }^{17}$

The degree of conversion of composite resins is influenced by the spectral distribution and intensity of the curing light as well as the shade, opacity, and chemical composition of the resin-based composite. While both LED lights and quartztungsten-halogen lights are believed capable of curing resin-based composites, some differences are observed in the performance of the cured resin. Moreover, both the composite material and its curing time have a significant association with the resulting degree of polymerization. ${ }^{18}$

It has been shown that LED light units, like conventional halogen light sources, are capable of curing the camphorquinone-based composites to an acceptable degree of polymerization ${ }^{19}$ and such resin composites show similar strain behavior whether an LED or halogen light curing unit is used to polymerize the resin composite. ${ }^{20}$

The ability to reduce exposure time by using high power LED or QTH lights may improve clinical time management. ${ }^{21}$ A very high power QTH light curing unit has been introduced into the market, claiming to cure resin composite with a thickness of more than $2 \mathrm{~mm}$ within a short exposure time. The aim of this study was to assess that high power light unit in terms of the curing performance and the temperature rise during irradiation as compared with those for a second-generation LED light source.

\section{MATERIALS AND METHODS}

A hybrid composite resin with A3 shade (Filtek Z250, 3M ESPE, St Paul, MN, USA) was used in this study as the test material. The curing light sources used in this study were a second-generation LED light unit with $860 \mathrm{~mW} / \mathrm{cm}^{2}$ intensity (Translux Power Blue, Heraeus Kulzer, Germanyl and a very high power QTH light unit with $2890 \mathrm{~mW} / \mathrm{cm}^{2}$ (Swiss Master Light, EMS, Switzerland). The light intensity of the units was checked using the builtin digital radiometer of an Optilux 501 light curing unit.

A two-split aluminum mold with a semicircular column-shaped hole $14 \mathrm{~mm}$ in diameter and $8 \mathrm{~mm}$ deepl was used to prepare samples for measuring the depth of cure and the hardness. The mold was placed on a sheet of Mylar strip and then the resin was compressed to produce a flat surface before it was covered by a clear polyester strip (Matrix Tape Refill, 3M) and finally was photopolymerized. For the control group, a Translux Power Blue (TPB) was used in continuous light photoactivation mode for $40 \mathrm{~s}$. Ten samples were prepared with the TPB light source. For the test group, a QTH light unit (EMS) was used in fast cure mode for either $4 \mathrm{~s}$ or $6 \mathrm{~s}$. Ten samples were prepared with the EMS light source for each exposure time $14 \mathrm{~s}$ or $6 \mathrm{~s})$. The cure depth of the resin was determined using a standard technique (ISO 4049:2000). Immediately after irradiation, the uncured material was scraped away with a spatula. The height of the cylinder of set resin was measured with a digital micrometer (Digital Cal, Switzerland) to a precision of $\pm 0.01 \mathrm{~mm}$, and the result was divided by two. Vickers hardness values were determined at $1.0 \mathrm{~mm}$ intervals along the depth of the cured samples, on a flat surface that was parallel to the direction of the light source, using a universal indenter (Leitz Wetzlar, Germany).

A digital thermometer (Temp Alert, Dual Thermo, Chinal was used to measure the temperature rise during exposure for a cured disc of resin composite (Filtek Z250, 3M, USA) with A3 shade, $2 \mathrm{~mm}$ thickness, and $13 \mathrm{~mm}$ diameter. A circular mold was prepared from an elastomeric base material in order to support the thermocouple under the cured resin disc. For each curing light and exposure time, groups of ten measurements were performed at 30 min intervals with the room temperature controlled.

The data were submitted to analysis of variance (ANOVA) as well as Tukey's and Student's t tests at the $5 \%$ significance level. 


\section{RESULTS}

Analysis of the data revealed significant $(P<.05)$ differences among the samples cured by the light sources in terms of Vickers hardness, depth of cure, and thermal changes during irradiation.

\section{Hardness}

The hardness values of the $0 \mathrm{~mm}, 1 \mathrm{~mm}$, and 2 $\mathrm{mm}$ levels all indicated significant differences between the samples cured by the TPB light unit and those cured by the EMS light unit (regardless of the $4 \mathrm{~s}$ or $6 \mathrm{~s}$ exposure time). Note that hardness values of the $3 \mathrm{~mm}$ and $4 \mathrm{~mm}$ levels were measurable only in those samples cured by the TPB light unit. Indeed, the maximum Vickers hardness values were produced by the TPB light unit, which gave $81.25,73.29,65.94,55.83$, and 24.53 for the $0 \mathrm{~mm}$ to $4 \mathrm{~mm}$ levels, respectively. The minimum hardness values were produced by the EMS light unit with a $4 \mathrm{~s}$ exposure time, which gave 73.27 , 61.51, and 31.59 for the $0 \mathrm{~mm}$ to $2 \mathrm{~mm}$ levels, respectively. Between the samples irradiated by the EMS light unit for $4 \mathrm{~s}$ and $6 \mathrm{~s}$, there was no significant difference in the hardness value at the $0 \mathrm{~mm}$ or $1 \mathrm{~mm}$ level, but there was at the $2 \mathrm{~mm}$ level. In samples cured with the TPB light unit, the $1 \mathrm{~mm}$ and $2 \mathrm{~mm}$ levels attained hardness values greater than or equal to $80 \%$ of the corresponding surface hardness values. In samples cured with the EMS light unit for $4 \mathrm{~s}$, only the $1 \mathrm{~mm}$ level attained $80 \%$ of the corresponding surface hardness values. In samples cured with the EMS unit for $6 \mathrm{~s}$, the $2 \mathrm{~mm}$ level attained hardness values that were closer to $80 \%$ of the corresponding surface hardness values than in samples cured for only $4 \mathrm{~s}$ (Table 1, Figure 1).

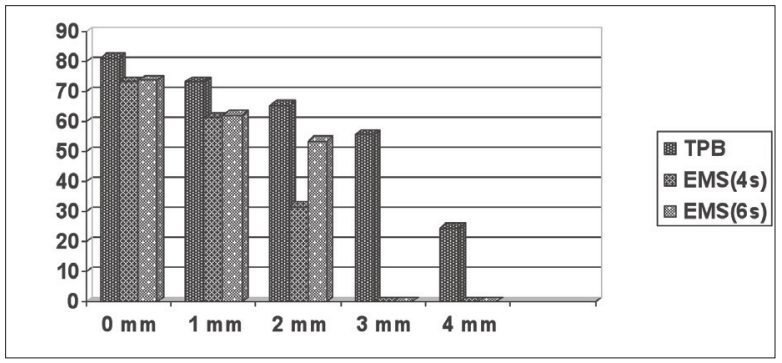

Figure 1. Vickers hardness values of resin composite at different intervals cured by different light sources and exposure time.
Depth of cure

The depth of cure (DOC) reached its maximum of $2.64 \mathrm{~mm}$ in samples cured by the LED light unit and its minimum of $2.00 \mathrm{~mm}$ in those cured by the QTH light with a $4 \mathrm{~s}$ exposure time. There was thus a significant $(P<.05)$ difference in $D O C$ between samples cured with the LED light unit and those cured with the QTH light unit. However, this significant difference was also found between samples cured with the EMS light unit for $4 \mathrm{~s}$ or $6 \mathrm{~s}$ of exposure time, since the DOC was $2.00 \mathrm{~mm}$ or 2.15 $\mathrm{mm}$, respectively.

\section{Thermal changes}

There was only an insignificant $(P>$.05) difference between the mean temperature rise generated by a $40 \mathrm{~s}$ irradiation with LED light $\left(1.87^{\circ} \mathrm{C}\right.$, $\mathrm{SD}=0.34)$ and that generated by a $4 \mathrm{~s}$ irradiation with QTH light $\left(1.88^{\circ} \mathrm{C}, \mathrm{SD}=0.19\right)$. However, for a 6 s irradiation with QTH light the analogous difference $\left(3^{\circ} \mathrm{C}, \mathrm{SD}=0.27\right)$ was considerable. Note that the difference in temperature rise between $4 \mathrm{~s}$ and 6 s of irradiation with the QTH light unit was also significant.

\section{DISCUSSION}

In this study, the curing performance of a high power halogen light unit (EMS) was matched against that of a second-generation LED light unit (TPB) with the aim of determining whether the halogen light unit with its short recommended exposure time is capable of curing composites as completely as the LED light unit with its $40 \mathrm{~s}$ irradiation time.

In general, larger hardness values are indicators of more extensive polymerization. ${ }^{22}$ The depth of cure for light activated dental resin composites has thus often been evaluated indirectly by measuring the hardness of the material at specific depths. ${ }^{23,24}$ It has been suggested that the depth of cure be defined as the level above which the hardness value of the cured resin composite is greater than or equal to $90 \%$ (or recently $80 \%$ ) of the surface hardness value..$^{25,26}$

The resin composite used in this study contains camphorquinone as the photoinitiator, and generally such resin composites can be more efficiently

Table 1. Vickers hardness values in different intervals and DOC of resin composite cured by light sources. SD is given in parenthesis.

\begin{tabular}{lcccccc}
\hline Intervals & $0 \mathrm{~mm}$ & $1 \mathrm{~mm}$ & $2 \mathrm{~mm}$ & $3 \mathrm{~mm}$ & $4 \mathrm{~mm}$ & DOC (mm) \\
\hline TPB & $81.25(1.61)$ & $73.29(0.88)$ & $65.49(1.00)$ & $55.83(1.40)$ & $24.53(6.05)$ & - \\
EMS (4s) & $73.27(1.17)$ & $61.51(0.84)$ & $31.59(0.39)$ & - & -64 & 2 \\
EMS (6s) & $73.74(0.78)$ & $62.16(1.02)$ & $53.52(1.01)$ & - & 2.15 \\
\hline
\end{tabular}


cured using LED light units. ${ }^{27}$ From $78 \%$ to $95 \%$ of the light emitted by a blue LED unit is within the wavelength range $450-500 \mathrm{~nm}$, as opposed to $56 \%$ for a conventional halogen unit.6,17 Therefore, only light within this range can best activate campherquinon. $^{28}$ However, some studies have indicated that a longer curing time is needed to reach a similar depth of cure and to create optimal performance for resin composite materials when using an LED light unit rather than a conventional tungsten halogen light unit. 29,30

For a given irradiation time, it can be anticipated that the microhardness of the composite decreases as the thickness of resin cured increases. In this study the LED light gave better performance than the high power halogen light with respect to hardness and depth of cure. In samples cured with the LED (TPB) light unit, the $1 \mathrm{~mm}$ and $2 \mathrm{~mm}$ levels attained hardness values greater than or equal to $80 \%$ of the corresponding surface hardness values. However, in the samples fast cured with the QTH (EMS) light unit, only the $1 \mathrm{~mm}$ levels attained $80 \%$ of the surface hardness values. The wavelength range of the LED light used in this study was 440-480 nm, which explains why greater degrees of hardness and conversion were achieved by this LED light with a $40 \mathrm{~s}$ irradiation than by the QTH light with either a $4 \mathrm{~s}$ or $6 \mathrm{~s}$ irradiation.

The halogen curing light produced significantly lower depth of cure (DOC) and hardness values than the LED curing light. Although the QTH light unit delivered a much greater power density, suggesting a higher degree of polymerization, the LED light benefitted from a much longer exposure time. The QTH light unit was only partly able to compensate for this difference, increasing the DOC but not the hardness of the resin composite. This result may be due to the reduced photoactivation time used by the EMS unit, representing a lower amount of energy ${ }^{31}$ and a shorter period of time for light to penetrate deeper into the material, since part of the light necessary for polymerization is absorbed and scattered by the resin composite that has already been polymerized. ${ }^{32}$

Another related factor may be that, although much emitted light can satisfy the camphorquinone (CQ) absorption curve and initiate a polymerization reaction, the highest probability of light absorption corresponds with the peak at $465 \mathrm{~nm}$. While the output of the halogen curing light has a broad spectrum, a great portion lies outside the $C Q$ absorption curve, so $80 \%$ of the energy from the halogen lamp is outside the useful curing range. . $^{7,33,34}$
A photoactivated resin-based composite can be fully polymerized at reduced light intensity while the final conversion value remains high. Curing the composite with a high intensity light and short exposure time, such as when using the EMS unit, shortens the pregelation phase and prevents a slow and ordered chain growth. ${ }^{35}$

According to manufacturer information, Filtek Z250 contains filler particles that range in size from 0.01 to $3.5 \mu \mathrm{m}$. Most activation light sources that are commercially available have a peak in the range 450-500 $\mathrm{nm}$. Research has shown that light scattering in the resin composite is maximal when the filler particle size is half the wavelength of the activating light, resulting in a lower transmission coefficient and smaller depth of cure. The transmission coefficient is influenced by the wavelength of the light, the refractive indices of the resin and fillers, and the nature and amount of the filler particles. $^{36}$ In comparison with the LED light, the EMS light has a much greater light intensity, which actually increases light scattering and light attenuation, resulting in less camphorquinone activation and resin conversion. This may also partly explain the decreased DOC in the samples cured with the EMS light in this study.

The light intensity and exposure time are known to be the most important factors in temperature change. ${ }^{37}$ Moreover, the temperature rise is known to increases with the power density of the LED or QTH unit, but yielding a greater rise for a given power density when using a QTH unit, as corroborated by the findings of this study. ${ }^{15}$

Another study indicated that photocuring blue light sources increase the temperature in tooth tissue during in situ polymerization of resin composite and that a higher power density QTH light source (Swiss Master Light) caused a greater increase in tooth temperature than a high power LED light. The temperature rise was greater with increased exposure time, as found in this study as well. ${ }^{38}$

In this study, increasing the period of irradiation with the QTH light from $4 \mathrm{~s}$ to $6 \mathrm{~s}$ only affected the DOC of the resin composite and the hardness of its $2 \mathrm{~mm}$ level. This can be partly attributed to a temperature rise by from $1.88^{\circ} \mathrm{C}$ to $3^{\circ} \mathrm{C}$ while curing the resin composite.

The thermal variations that occur during the photoactivation of composite resins are related both to the exothermic polymerization of the materials and to the heat output from the dental curing light units. A cured composite, such as the cured composite disc in this study, is capable of 
reducing the ability of irradiated light to increase temperature. This has been shown by a study in which the temperature rise caused by irradiation was less via a previously cured composite than via an initially unpolymerized composite. ${ }^{39}$

According to the results of this study, composite increments less than $2 \mathrm{~mm}$ in thickness should be cured using a high power QTH light source for a short period of time, especially in deep cavities to ensure proper curing of the composite. Applying thicker increments and increasing the exposure time to compensate will increase temperature rise and endanger pulp chamber vitality.

\section{CONCLUSIONS}

- Hardness values produced were greater with the LED light than with the QTH light.

- Depth of cure obtained was higher with the LED light.

- Depth of cure produced by the QTH light was higher for a recommended $6 \mathrm{~s}$ irradiation than for a shorter $4 \mathrm{~s}$ exposure.

- Thermal changes were greater using the QTH light for $6 \mathrm{~s}$ than using it for $4 \mathrm{~s}$ or the LED light for $40 \mathrm{~s}$.

- Thermal changes were the same whether using the LED light for $40 \mathrm{~s}$ or the QTH light for $4 \mathrm{~s}$.

\section{REFERENCES}

1. Mills RW, Uhl A, Jandt KD. Optical power outputs, spectra and dental composite depths of cure, obtained with blue light emitting diode (LED) and halogen light curing units (LCUs). Br Dent J 2002;193:459-463.

2. Dunn WJ, Bush AC. A comparison of polymerization by light-emitting diode and halogen-based light-curing units. J Am Dent Assoc 2002;133:335-341.

3. Soh MS, Yap AU, Siow KS. Effectiveness of composite cure associated with different curing modes of LED lights. Oper Dent 2003;28:371-377.

4. Uhl A, Mills RW, Vowles RW, Jandt KD. Knoop hardness depth profiles and compressive strength of selected dental composites polymerized with halogen and LED light curing technologies. J Biomed Mater Res 2002;63:729-738.

5. Uhl A, Mills RW, Jandt KD. Photoinitiator dependent composite depth of cure and Knoop hardness with halogen and LED light curing units. Biomaterials 2003;24:1787-1795.

6. Mills RW, Uhl A, Blackwell GB, Jandt KD. High power light emitting diode (LED) arrays versus halogen light polymerization of oral biomaterials: Barcol hardness, compressive strength and radiometric properties. Biomaterials 2002;23:2955-2963.
7. Wiggins KM, Hartung M, Althoff 0 , Wastian C, Mitra SB. Curing performance of a new-generation light-emitting diode dental curing unit. J Am Dent Assoc 2004;135:14711479.

8. Tseng WY, Chen RS, Wang JL, Lee MS, Rueggeberg FA, Chen $\mathrm{MH}$. Effects on microstrain and conversion of flowable resin composite using different curing modes and units. J Biomed Mater Res B Appl Biomater 2007;81:323-329.

9. Knezevic A, Tarle Z, Meniga A, Sutalo J, Pichler G, Ristic M. Degree of conversion and temperature rise during polymerization of composite resin samples with blue diodes. $J$ Oral Rehabil 2001;28:586-591.

10. Hofmann N, Hugo B, Klaiber B.Effect of irradiation type (LED or QTH) on photo-activated composite shrinkage strain kinetics, temperature rise, and hardness. Eur J Oral Sci 2002;110:471-479.

11. Ozturk B, Ozturk AN, Usumez A, Usumez S, Ozer F. Temperature rise during adhesive and resin composite polymerization with various light curing sources. Oper Dent 2004:29:325-332.

12. Weerakoon AT, Meyers IA, Symons AL, Walsh LJ. Pulpal heat changes with newly developed resin photopolymerisation systems. Aust Endod J 2002;28:108-111.

13. Knezevic A, Tarle Z, Meniga A, Sutalo J, Pichler G. Influence of light intensity from different curing units upon composite temperature rise. J Oral Rehabil 2005;32:362-367.

14. Tarle Z, Knezevic A, Demoli N, Meniga A, Sutaloa J, Unterbrink G, Ristic M,Pichler G. Comparison of composite curing parameters: effects of light source and curing mode on conversion, temperature rise and polymerization shrinkage. Oper Dent 2006;31:219-226.

15. Guiraldo RD, Consani S, Lympius T, Schneider LF, Sinhoreti MA, Correr-Sobrinho L. Influence of the light curing unit and thickness of residual dentin on generation of heat during composite photoactivation. J Oral Sci 2008;50:137142.

16. Hannig M, Bott B. In-vitro pulp chamber temperature rise during composite resin polymerization with various lightcuring sources. Dent Mater 1999;15:275-281.

17. Asmussen E, Peutzfeldt A. Temperature rise induced by some light emitting diode and quartz-tungsten-halogen curing units. Eur J Oral Sci 2005;113:96-98.

18. Aravamudhan K, Floyd CJ, Rakowski D, Flaim G, Dickens $\mathrm{SH}$, Eichmiller FC, Fan PL. Light-emitting diode curing light irradiance and polymerization of resin-based composite. J Am Dent Assoc 2006;137:213-223.

19. Hasler C, Zimmerli B, Lussi A. Curing capability of halogen and LED light curing units in deep class II cavities in extracted human molars. Oper Dent 2006;31:354-363. 
20. Uhl A, Mills RW, Rzanny AE, Jandt KD. Time dependence of composite shrinkage using halogen and LED light curing. Dent Mater 2005;21:278-286.

21. Felix CA, Price RB, Andreou P. Effect of reduced exposure times on the microhardness of 10 resin composites cured by high-power LED and QTH curing lights. J Can Dent Assoc 2006;72:147.

22. Asmussen E. Restorative resins: hardness and strength vs. quantity of remaining double bonds. Scand J Dent Res 1982;90:484-489.

23. Ferracane JL. Correlation between hardness and degree of conversion during the setting reaction of unfilled dental restorative resins. Dent Mater 1985;1:11-14.

24. Johnston WM, Leung RL, Fan PL. A mathematical model for post-irradiation hardening of photoactivated composite resins. Dent Mater 1985;1:191-194.

25. DeWald JP, Ferracane JL. A comparison of four modes of evaluating depth of cure of light-activated composites. $J$ Dent Res 1987;66:727-730.

26. Aravamudhan K, Floyd CJ, Rakowski D, Flaim G, Dickens $\mathrm{SH}$, Eichmiller FC, Fan PL. Light-emitting diode curing light irradiance and polymerization of resin-based composite. J Am Dent Assoc 2006;137:213-223.

27. Ernst CP, Meyer GR, Muller J, Stender E, Ahlers MO, Willershausern B. Depth of cure of LED vs QTH light-curing devices at a distance of $7 \mathrm{~mm}$. J Adhes Dent 2004;6:141-150.

28. Cook WD. Spectral distributions of dental photopolymerization sources. J Dent Res 1982;61:1436-1438.

29. Besnault C, Pradelle-Plasse N, Picard B, Colon P. Effect of a LED versus halogen light cure polymerization on the curing characteristics of three composite resins. Am J Dent 2003; 16:323-328.

30. Nomoto R, McCabe JF, Hirano S. Comparison of halogen, plasma and LED curing units. Oper Dent 2004;29:287-294.

31. Miyazaki M, Oshida Y, Moore BK, Onose H. Effect of light exposure on fracture toughness and flexural strength of light-cured composites. Dent Mater 1996;12:328-332.

32. Baharav H, Abraham D, Cardash HS, Helft M. Effect of exposure time on the depth of polymerization of a visible light-cured composite resin. J Oral Rehabil 1988;15:167172.

33. Mills RW, Jandt KD, Ashworth SH. Dental composite depth of cure with halogen and blue light emitting diode technology. Br Dent J 1999;186:388-391.

34. Kurachi C, Tuboy AM, Magalhaes DV, Bagnato VS. Hardness evaluation of a dental composite polymerized with experimental LED-based devices. Dent Mater 2001;17:309315
35. Tarle Z, Knezevic A, Demoli N, Meniga A, Sutaloa J, Unterbrink G, Ristic M, Pichler G. Comparison of composite curing parameters: effects of light source and curing mode on conversion, temperature rise and polymerization shrinkage. Oper Dent 2006;31:219-226.

36. Kawaguchi M, Fukushima T, Miyazaki K. The relationship between cure depth and transmission coefficient of visiblelight-activated resin composites. J Dent Res 1994;73:516521.

37. Guiraldo RD, Consani S, Lympius T, Schneider LF, Sinhoreti MA, Correr-Sobrinho L. Influence of the light curing unit and thickness of residual dentin on generation of heat during composite photoactivation. J Oral Sci 2008;50:137142.

38. Bouillaguet S, Caillot G, Forchelet J, Cattani-Lorente M, Wataha JC, Krejci I. Thermal risks from LED- and highintensity QTH-curing units during polymerization of dental resins. J Biomed Mater Res B Appl Biomater 2005;72:260-267.

39. Stewardson DA, Shortall AC, Harrington E, Lumley PJ. Thermal changes and cure depths associated with a high intensity light activation unit. J Dent 2004;32:643-651. 